О. С. Улічев

Центральноукраїнський національний технічний університет, Кропивницький, Україна

\title{
ДОСЛДЖЕННЯ МОДЕЛЕЙ РОЗПОВСЮДЖЕННЯ ІНФОРМАЦІї ТА ІНФОРМАЦІЙНИХ ВПЛИВІВ В СОЦІАЛЬНИХ МЕРЕЖАХ
}

\begin{abstract}
Предметом вивчення в статті $€$ процеси розповсюдження інформації та інформаційних впливів у віртуальних соціальних мережах. Метою $\epsilon$ дослідження існуючих моделей розповсюдження інформації та інформаційних впливів у віртуальних соціальних мережах, порівняння окремих моделей, виявлення характеристик та специфічних ознак, що не враховуються в існуючих моделях. Завдання: дослідити види існуючих, раніше запропонованих, моделей для моделювання інформаційних процесів в соціальних мережах, провести порівняльний аналіз для виявлення характеристик та проявів, що не враховуються в запропонованих моделях, і в той же час можуть мати суттєвий вплив на досліджувані процеси. Використаними методами $€$ : аналіз та синтез, емпіричні методи порівняння. Отримано наступні результати: порівняння розглянутих моделей виявляе, що більшість 3 них не враховують індивідуальних характеристик вузла. Класичні моделі орієнтовані на дослідження певних підгруп вузлів мережі та динаміку зміни даних підгруп, при цьому всі вузли мають однакові характеристики. Практика дослідження ситуацій в реальних умовах показує суттєвість значення та впливу на процес особистих характеристик учасників процесу інформаційного обміну. В тому числі існуючі моделі не враховують і поведінки чи стратегій, що обираються окремими вузлами в ході реалізації процесів інформаційного впливу. Висновки. Щоб узагальнити поведінку конкретних учасників мережі на всю мережу, необхідно створення єдиної теорії соціальних мереж, в рамках якої можна було б вивчати методи виявлення і опису характеристик мереж, закономірності поширення цих характеристик, створення методів, що дозволяють за структурою соціальної мережі та іншими характеристиками визначати причини взаємодій учасників. Наявність великої кількості запропонованих моделей потребує комплексного підходу до порівняння та оцінки моделей. Інформаційні впливи ботів та автоматизований підхід до процесу розповсюдження інформації втрачають свою актуальність за рахунок наявності розроблених методів для розпізнавання та нейтралізації таких впливів. В ході «живого спілкування» та інформаційних процесів між людьми - вузлами мережі вирішальне значення мають характеристики окремо взятого вузла та обрана ним поведінкова стратегія для досягнення поставленої мети. Як показує проведене дослідження - більшість існуючих моделей дані аспекти не враховує.
\end{abstract}

Ключов і слов а : соціальна мережа, інформаційний вплив, моделювання процесів інформаційного обміну, моделювання соціальних мереж, поширення інформації, поведінкова стратегія.

\section{Вступ}

Одним 3 нових, але досить перспективним напрямком наукових досліджень $є$ вивчення соціальних мереж в цілому, та зокрема розповсюдження інформації в мережі.

Дослідження в даному напрямку викликають зацікавлення в багатьох прикладних напрямках, в аналізі тенденцій та динаміки розповсюдження інформації в соціальних мережах (CM) зацікавлені маркетологи 3 точки зору просування товарів на ринки, 3 тих же міркувань даним напрямком цікавляться і бізнес-аналітики. Іншим проявом явища розповсюдження інформації в СМ є інформаційний вплив (IB) та переконання людей в певній ідеї, з цієї точки зору процес цікавить політиків, PRменеджерів, політтехнологів та пропагандистів.

Інструменти аналізу дозволяють оцінити індивідуальні та групові переваги клієнтів, виявити тренди інтересів і надалі вирішувати важливі стратегічні завдання.

Одним 3 основних завдань і засобів інформаційного обміну соціальних мереж $є$ поширення інформації: статті, огляди, аудіо, відео, короткі повідомлення («Твіти») та інші види інформації в сукупності утворюють інформаційний контент соціальних мереж.

Значний інтерес до даного питання сприяв його науковому дослідженню, за останні десятиліття науковцями запропоновано ряд методів та засобів ана- лізу і дослідження СМ в різних їх проявах. Одним 3 методів дослідження є моделювання.

Метою даної роботи $\epsilon$ дослідження моделей розповсюдження інформації та інформаційних впливів в соціальних мережах 3 погляду використання їх для аналізу комп'ютерних соціальних мереж, зокрема, для аналізу взаємодій між учасниками мережі, прогнозування їх поведінки, класифікації учасників, моделювання інформаційних потоків в мережах та динаміки їх розповсюдження.

Велика кількість існуючих підходів дослідження СМ призвела до необхідності їх класифікації, науковці виділяють декілька напрямків дослідження СМ, зокрема автори [1] класифікують дослідження СМ по чотирьом основним напрямкам: структурний, ресурсний, нормативний та динамічний. В даній роботі будуть розглядатись моделі, що в більшості відносяться до структурного підходу, а також мають ознаки динамічного підходу.

У структурному підході всі учасники мережі розглядаються як вершини графу, які впливають на конфігурацію ребер і інших учасників мережі. Основна увага приділяється геометричній формі мережі та інтенсивності взаємодій (вазі ребер), тому досліджуються такі характеристики, як взаємне розташування вершин, центральність [2], транзитивність взаємодій.

Динамічний підхід аналізує зміни в структурі мережі: появу нових учасників, утворення стійких підструктур, динаміку зміни зв'язків. 


\section{1. Модель епідемії та похідні моделі}

Перші моделі для дослідження СМ запропоновані достатньо давно, зокрема варто розглянути модель епідемії, або SIR (Susceptibles - Infectives Removed). Дана модель запропонована вперше авторами Кермаком та МакКендріком в роботі [3]. Початково модель запропонована для прогнозування розповсюдження епідемій, модель пропонує поділити населення на три групи $\mathrm{S}$ - сприятливі до захворювання, I - інфіковані, R - одужали та мають імунітет. Автори моделі запропонували систему диференційних рівнянь що описує процес розповсюдження хвороби:

$$
\left\{\begin{array}{l}
\frac{\mathrm{d} S}{\mathrm{~d} t}=-\frac{\beta \cdot I \cdot S}{N} ; \\
\frac{\mathrm{d} I}{\mathrm{~d} t}=\frac{\beta \cdot I \cdot S}{N}-\gamma \cdot I ; \\
\frac{\mathrm{dR}}{\mathrm{d} t}=\gamma \cdot I,
\end{array}\right.
$$

де $\beta$ - середня частота зараження; $\gamma$-стала середня швидкість одужання; $\mathrm{N}$ - загальна кількість особин популяції (кількість населення).

Розповсюдження хвороби багато в чому подібне до розповсюдження інформації в мережі, але дослідження показують що результати моделювання на SIR досить сильно розбігаються 3 результатами експерименту проведеного на реальній моделі [4]. Основним недоліком даної моделі $є$ те, що вона не враховує динаміки зміни кількості вузлів мережі в часі: окремі користувачі можуть приєднуватись до мережі або, навпаки, покидати мережу вибуваючи 3 ланцюга розповсюдження інформації. Тому для моделювання соціальної мережі було запропоновано розширену модель SIR. Розширена модель доповнена параметрами $\mu$ - середня частота залучення нового агента в мережу, $\delta$ - середня частота покидання мережі окремим агентом. Розширення набору параметрів дозволило більш точно наблизити модель до реальних показників. Взявши за основу модель SIR в 1965 році була запропонована модель ДалеяКендалла (DK-модель), дана модель відома ще як «модель розповсюдження чуток». В своїй моделі автори дещо змінили критерії розбиття населення на групи порівняно з моделлю SIR i виділили такі групи: $U$ - група, що починає розповсюдження чутки (новини); $V$ - група, що сприймає чутку і продовжує iii розповсюдження; $W$ - група, що не сприймає інформації і не розповсюджує іiі далі.

Як бачимо, в моделі «розповсюдження чуток» виділено все ті ж три групи але їх інтерпретація адаптована саме до процесу інформаційного обміну. В DK-моделі чутка розповсюджується 3 ймовірністю $\beta / N$, а ступінь сприйняття визначається параметром $\mu$. Розповсюдження припиняється якщо, розповсюджуючи, агент натикається на представника групи $W$, ймовірність даного факту визначається співвідношенням:

$$
\gamma \cdot V \cdot(V+W) / N
$$

\section{2. Моделі на основі клітинних автоматів}

Окремим напрямком в моделюванні мереж $є$ моделі на основі клітинних автоматів. В основі таких моделей лежить дискретна динамічна система, що складається з однорідних клітин. Кожна клітина може мати певний набір станів та правила переходу від одного стану до іншого. На перехід клітини до іншого стану впливають інші клітини, що оточують iii. Моделі відрізняться наборами станів та правилами переходу. Дані моделі враховують до певної міри динаміку та структуру мережі: окіл кожної окремо взятої клітини та стан оточуючих клітин. Дані моделі в деяких джерелах називають моделями дифузії інновацій. Формально клітинний автомат може бути описаний співвідношенням:

$$
y_{j}(t+1)=F\left(y_{j}(t), O(j), T\right),
$$

де $t$ - крок ітерації; $F$ - формально представлене правило переходу до іншого стану; $y_{j}(t)$ - стан на попередній ітерації; $O(j)$ - множина сусідніх клітин (окіл кінцевого клітинного автомату). В найпростішому випадку для клітинного автомату можна визначити стани аналогічні критерію розподілу на підмножини DK-моделі (сприймає новину, сприймає і розповсюджує, не сприймає). Більш адекватно модель відображає процес, якщо розширити набір станів та ускладнити правила переходів. Наприклад деякі автори пропонують враховувати параметр старіння новини та використовувати систему порогів.

Розглянуті вище моделі являються класичними моделями для оцінки інформаційного «зараження», але цікавим $є$ також і дослідження розподілу думок i впливів.

\section{3. Моделі 3 порогами та моделі незалежних каскадів}

На системі порогів побудовані так звані порогові моделі. Їх суть полягає в тому, що агенти поділяються на активних (ті, що розповсюджують інформацію) та неактивних. Моделюється ітераційний процес, в ході інформаційного обміну в кожного окремого агента накопичується рівень інформаційного впливу та існує певний поріг. При переході даного порогу агент стає активним, при цьому перехід розглядається як незворотній. Якщо функція накопичення є лінійною такі моделі відокремлюють в окремий клас - «Моделі з лінійним порогом».

Подібною по суті $є$ і модель незалежних каскадів, але суттєвою відмінністю від попередньої $є$ те, що вузол $v_{i}$ може лише однократно (з певною ймовірністю) впливати на вузол $v_{j}$. Такі моделі відносять до класу систем взаємодії незалежник частинок. В роботі [5] описана узагальнююча модель, для якої порогові моделі та моделі незалежних каскадів є частковими випадками.

\section{4. Моделі 3 використанням ланцюгів Маркова}

Запропоновано моделі, що враховують події властиві виключно соціальним мережам. Прикладом такої моделі можна навести мультиагентну модель 
розповсюдження інформації в мережі запропоновану Ланде Д.В. та співавторами в статті [6], дану модель варто віднести до моделі, що базується на ланцюгах Маркова. В якості базового параметра моделі автори пропонують розглядати деяку величину $E$ (енергія агента) в процесі моделювання ітераційного процесу розповсюдження інформації, з певною ймовірністю можуть відбуватись події, що змінюють рівень енергії агента:

$$
\begin{aligned}
& \text { Лайк }=E+1, \text { Дизлайк }=E-1, \\
& \text { Репост }=E+2, \text { Лінк }=E+1 .
\end{aligned}
$$

Окрім зовнішніх впливів агент за умовами моделі втрачає по 1 одиниці енергії на кожній ітерації моделі. Ймовірність виникнення подій залежить від ряду факторів: актуальність повідомлення, рівень зацікавленості в інформації, інші характеристичні зовнішні оцінки інформаційного повідомлення. Ймовірності того, що внаслідок повідомлення з енергією агента відбувається певна зміна автори визначили таким чином:

$$
\begin{aligned}
& P_{\text {like }}^{(E)}=P_{l_{0}} \cdot \varphi(E) ; \\
& P_{\text {dislike }}^{(E)}=P_{d_{0}} \cdot \varphi(E) ; \\
& P_{\text {repost }}^{(E)}=P_{r_{0}} \cdot \varphi(E),
\end{aligned}
$$

де $P_{l_{0}}, P_{d_{0}}, P_{r_{0}}$ - параметри моделі; а $\varphi(E) \in[0,1]-$ деяка монотонно неспадаюча функція.

При падінні значення енергії агенту до $0-$ він «помирає» і більше в моделі не розглядається. Життєвий цикл моделі пропонується починати з одного агента, його можна представити графом (рис. 1).

Досліджуючи ймовірнісний розподіл послідовності через ймовірність переходів при фіксованих початкових параметрах, дослідники приходять до висновку - розподіл ймовірності отримання агентом $n$ лайків відповідає розподілу Вейбулла. Дуже схожі данні були отримані і в ході експерименту, проведеного авторами моделі, 3 даними отриманими 3 реальної мережі.

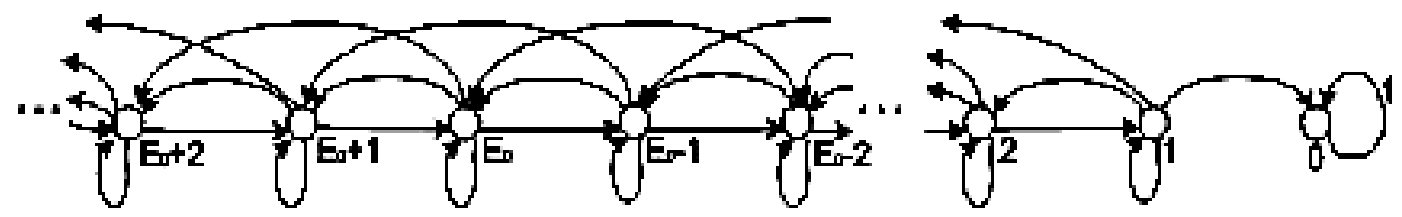

Рис. 1. Представлення моделі з використанням ланцюгів Маркова графом

\section{5. Ігрові моделі}

Окремий вид моделей - так звані «теоретикоігрові» моделі. Вклад в розвиток цієї гілки та грунтовні дослідження проведені в роботах Губанова Д.А., Новікова Д.А., Чхартішвілі А.Г. [8, 9, 10]. В моделях даного типу акцент робиться на інформованість і взаємозв'язок між гравцями (агентами). Загалом автори пропонують триступеневу ієрархічну задачу (рис. 2).

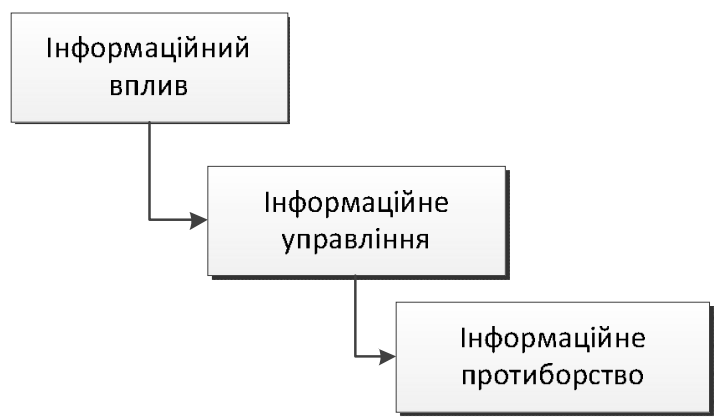

Рис. 2. Іерархічна структура задач дослідження інформаційних процесів

Ігрова модель розглядає початкові умови гри, кінцеву мету гравця та дії опонентів (інших учасників гри). Агент вибудовує свою гру таким чином, щоб максимізувати свою вигоду з урахуванням поточних умов. Теоретико-ігрові моделі розглядаються в залежності від кінцевої мети, серед них виділяють такі класи:

1) моделі взаємної інформованості;

2) моделі узгоджених колективних дій (i суспільних благ);
3) моделі комунікацій і завдання пошуку мінімально-достатньої мережі;

4) моделі стабільності мережі;

5) моделі інформаційного впливу та управління;

6) моделі інформаційного протиборства.

В залежності від типу моделі визначаються правила гри і можлива поведінка гравця для досягнення кінцевої мети.

\section{6. Порівняння моделей}

Порівняння моделей ускладнюється і вибором критеріїв для порівняння і різною внутрішньою структурою та математичною природою моделей. Зрозумілим є той факт, що кожна 3 моделей має своє спрямування та базується на певних вичлененнях 3 реального процесу: окремо взяті характеристики i властивості.

Запропонована порівняльна таблиця (табл. 1) не розподіляє моделі на «кращі» та «гірші», а лише визначає характеристики та прояви, що враховуються моделлю. 3 табл. 1 видно, що серед розглянутих моделей жодна не дає комплексного представлення процесу і лише частково враховує окремі характеристики, що притаманні й впливають на реальний процес розповсюдження інформації в СМ. 3 урахуванням оцінок в табл. 1, найкращий результат на наборі критеріїв показують теоретико-ігрові моделі, але тут необхідно враховувати й той факт, що теоретико-ігрові моделі представляють собою цілий набір класів. Кожна окрема модель враховує, в тій чи іншій мірі, окремі характеристики. 3 табл. 1 видно, що більшість моделей не враховують активності агента, його поведінкових стратегій в життєвому циклі процесу. 
Таблиия 1. Врахування різних властивостей моделями

\begin{tabular}{|c|c|c|c|c|c|c|c|c|c|}
\hline $\begin{array}{ll}\text { Моделі } & \text { Властивості } \\
\end{array}$ & 1 & 2 & 3 & 4 & 5 & 6 & 7 & 8 & 9 \\
\hline Моделі зараження & - & - & - & + & - & - & - & + & - \\
\hline Моделі з порогами & + & + & + & - & - & + & - & - & - \\
\hline Моделі незалежних каскадів & + & $+/-$ & - & + & - & + & - & - & - \\
\hline Клітинні автомати & + & + & + & - & - & + & - & $+/-$ & - \\
\hline Моделі на основі ланцюгів Маркова & + & - & - & + & - & - & - & + & $+/-$ \\
\hline Теоретико-ігрові моделі & + & + & $+/-$ & $+/-$ & $+/-$ & + & + & - & $+/-$ \\
\hline
\end{tabular}

Стовпці таблиці: 1 - зміна думки під впливом оточуючих агентів;

2 - вплив структурних особливостей околу агента, та структури мережі в цілому;

3 - різний ступінь схильності агентів до IB; $\mathbf{4}$ - наявність ймовірнісних параметрів;

5 - врахування активності агента; 6 - оптимізація IB;

7 - поведінкові стратегії агентів (ігрова взаємодія) ;

8 - оцінка ймовірності певного результату та розподіл агентів в визначений момент часу;

9 - параметризація особистісних якостей агента.

Більшість класичних моделей взагалі не розглядають параметрів агента, всі агенти в цих моделях ідентичні. Ці недоліки суттєво знижують адекватність моделей, бо в реальній ситуації соціальна мережа складається 3 особистостей 3 індивідуальними якостями та характеристиками. Поведінка окремого агента звичайно має суттєвий локальний вплив, але, в той же час, це може вплинути і на кінцевий результат чи стан мережі відносно досліджуваного інформаційного впливу. Будь-який інформаційний вплив, розповсюдження новини чи лобіювання певної ідеї в мережі починається з одного (або невеликої обмеженої групи) агентів, і на початковому етапі суттєве значення має саме стратегія і особливі якості агентагенератора. В найгіршому для нього випадку інформація взагалі може не набути розповсюдження, або канали й способи розповсюдження будуть обрані невірно й інформаційна хвиля швидко згасне.

\section{Висновки}

Для того, щоб робити певні висновки про процеси, що протікають в суспільстві, прогнозувати поведінку його учасників, моделювати соціальну взаємодію, необхідно здійснювати аналіз інформації, яка існує в соціальних мережах. Тому створення нових та інтеграція вже створених методів і моделей аналізу комп'ютерних соціальних мереж становить інтерес для дослідження. Існування різних підходів до аналізу комп'ютерних соціальних мереж призводить до проблеми об'єднання результатів, отриманих в ході досліджень. У дослідженні атрибутів учасників мережі, зв'язків між ними, виявленні закономірностей побудови мереж між учасниками можуть бути корисні нові методи статистичного аналізу, комбінації їх з алгоритмами 3 теорії графів та програмними ітераційними моделями. Іноді відносини між учасниками мережі зручно розглядати як імовірнісні (стохастичні) характеристики для опису процесу еволюції мереж, в інших випадках можуть бути використані моделі з детермінованими наборами правил.

Щоб узагальнити поведінку конкретних учасників мережі на всю мережу, необхідно створення єдиної теорії соціальних мереж, в рамках якої можна було б вивчати методи виявлення і опису характеристик мереж, закономірності поширення цих характеристик, створення методів, що дозволяють за структурою соціальної мережі та іншими характеристиками визначати причини взаємодій учасників.

Як показує огляд джерел, сьогодні дослідники пропонують як комбіновані комплексні моделі, що мають підвищити адекватність і відповідність моделювання реальним процесам, так і моделі орієнтовані на дослідження конкретного питання чи характеристики. Перші стикаються з проблемами математичного характеру, суттєвого ускладнення структури моделі внаслідок нашарування параметрів і породженням різного роду колізій. Другі стикаються 3 ризиками отримання великих похибок в результаті відкидання певних характеристик та параметрів.

\section{СПИСОК ЛІТЕРАТУРИ}

1. Батура Т.В. Модели и методы анализа компьютерных социальных сетей // Программные продукты и системы 2013. № 3 C. $130-137$.

2. Мелешко Є.В. Дослідження методів визначення центральності акторів у соціальних мережах для задач інформаційної безпеки / Є.В. Мелешко, В.С. Гермак, С.М. Охотний / Збірник наукових праць "Системи управління, навігації та зв'язку". Випуск 4(40). - Полтава: ПНТУ ім. Ю. Кондратюка. - 2016. - С. 67-70.

3. Kermack W.O., McKendrick A.G. A Contribution to the Mathematical Theory of Epidemics// Proc. of the Royal Society A: Mathematical, Physical and Engineering Sciences. 1927. No. 115 (772). 700 p. DOI:10.1098/rspa.1927.0118. JSTOR 94815.

4. Горковенко Д.К. Сравнительный анализ моделей эпидемии и клеточного автомата при моделировании распространения информации в социальных сетях // Научно-технические ведомости СПбГПУ. Информатика. Телекоммуникации. Управление. 2017. Т. 10. № 3. С. 103-113. DOI: 10.18721/JCSTCS.10309

5. Kempe D., Kleinberg J., Tardos E. Maximizing the Spread of Influence through a Social Network / Proceedings of the 9-th ACM SIGKDD International Conference on Knowledge Discovery and Data Mining. - 2003. - p. 137-146.

6. Ландэ Д.В., Грайворонская А.Н., Березин Б.А. Мультиагентная модель распостранения информации в социальной сети// Системи збереження та масового розповсюдження даних: Реєстрація, зберігання і обробка даних, 2016, Т.18, 
№1

7. Чураков А.Н. Анализ социальных сетей // Социологические исследования. 2001. № 1. С. 109-121.

8. Губанов Д.А., Новиков Д.А., Чхартишвили А.Г. Модели информационного влияния и информационного управления в социальных сетях // Проблемы управления. 2009.

9. Губанов Д.А., Новиков Д.А., Чхартишвили А.Г. Модели репутации и информационного управления в социальных сетях // Управление большими системами. 2009.

10. Чхартишвили А.Г. Теоретико-игровые модели информационного управления. - М.: ПМСОФТ, 2005.

Рецензент: д-р техн. наук, проф. С. Г. Семенов, Національний технічний університет “Харківський політехнічний інститут”, Харків Received (Надійшла) 12.06.2018 Accepted for publication (Прийнята до друку) 15.08.2018

\title{
Исследование моделей распространения информации и информационных воздействий в социальных сетях
}

\author{
А.С. Уличев
}

Предметом изучения в статье являются процессы распространения информации и информационных воздействий в виртуальных социальных сетях. Целью является исследование существующих моделей распространения информации и информационных воздействий в виртуальных социальных сетях, сравнение отдельных моделей, выявление характеристик и специфических признаков, которые не учитываются в существующих моделях. Задача: исследовать виды существующих, ранее предложенных, моделей для моделирования информационных процессов в социальных сетях, провести сравнительный анализ для выявления характеристик и проявлений, которые не учитываются в предложенных моде-лях, и в то же время могут иметь существенное влияние на исследуемые процессы. Использованными методами являются: анализ и синтез, эмпирические методы сравнения. Получены следующие результаты: сравнение рассмотренных моделей обнаруживает, что большинство из них не учитывают индивидуальных характеристик узла. Классические модели ориентированы на исследование определенных подгрупп узлов сети и динамику изменения данных подгрупп, при этом все узлы имеют одинаковые характеристики. Практика исследования ситуаций в реальных условиях показывает существенность значения и влияния на процесс личностных характеристик участников процесса информационного обмена. В том числе существующие модели не учитывают и поведения или стратегий, избираемых отдельными узлами в ходе реализации процессов информационного воздействия. Выводы. Чтобы обобщить поведение конкретных участников сети на всю сеть, необходимо создание единой теории социальных сетей, в рамках которой можно было бы изучать методы выявления и описания характеристик сетей, закономерности распространения этих характеристик, создание методов, позволяющих по структуре социальной сети и другим характеристикам определять причины взаимодействий участников. Наличие большого количества предложенных моделей требует комплексного подхода к сравнению и оценке моделей. Информационные влияния ботов и автоматизированный подход к процессу распространения информации теряют свою актуальность за счет наличия разработанных методов для распознавания и нейтрализации таких воздействий. В ходе «живого общения» и информационных процессов между людьми-узлами сети решающее значение имеют характеристики отдельно взятого узла и выбранная им поведенческая стратегия для достижения поставленной цели. Как показывает проведенное исследование - большинство существующих моделей данные аспекты не учитывает.

Ключевые слова: социальная сеть, информационное воздействие, моделирование процессов информационного обмена, моделирование социальных сетей, распространение информации, поведенческая стратегия.

\section{Research of the models of information dissemination and information influences in social networks}

$$
\text { O.S. Ulichev }
$$

The subject matter of the article is the processes of dissemination of information and information influences in virtual social networks. The goal is research existing models of information dissemination and information influences in virtual social networks, carry out the comparative analysis existing models, identify characteristics and specific features that are not taken into account in existing models. The tasks to be solved are: to investigate the types of existing, previously proposed models for modeling information processes in social networks, to perform a comparative analysis to identify characteristics and manifestations that are not taken into account in the proposed models, and at the same time may have a significant impact on the processes under study. The methods used are: analysis and synthesis, empirical comparison methods. The following results were obtained: a comparison of the models considered reveals that most of them do not take into account the individual characteristics of the node. Classical models are focused on the study of certain subgroups of network nodes and the dynamics of changes in these subgroups, with all nodes have the same characteristics. The practice of studying situations in real conditions shows the significance of the importance and influence on the process of personal characteristics of the participants in the information exchange process. Including existing models do not take into account the behavior or strategies selected by individual nodes during the implementation of information impact processes. Conclusions. In order to generalize the behavior of specific network participants to the whole network, it is necessary to create a unified theory of social networks, within which one could study methods for identifying and describing the characteristics of networks, the patterns of propagation of these characteristics, the creation of methods that, in terms of the social network structure and other characteristics, participants. The presence of a large number of proposed models requires an integrated approach to comparison and evaluation of models. The information influence of bots and the automated approach to the information dissemination process are losing their topicality due to the availability of developed methods for recognizing and neutralizing such impacts. In the course of "live communication" and information processes between people - network nodes, the characteristics of a single node and the chosen behavioral strategy for achieving the set goal are crucial. As the study shows, most models do not consider these aspects.

Keywords: social network, information influence, modeling of information exchange processes, social network modeling, information dissemination, behavioral strategy. 